\title{
Etifoxine improves sensorimotor deficits and reduces glial activation, neuronal degeneration, and neuroinflammation in a rat model of traumatic brain injury
}

Emmanuelle Simon-O'Brien*, Delphine Gauthier, Véronique Riban and Marc Verleye

\begin{abstract}
Background: Traumatic brain injury (TBI) results in important neurological impairments which occur through a cascade of deleterious physiological events over time. There are currently no effective treatments to prevent these consequences. TBI is followed not only by an inflammatory response but also by a profound reorganization of the GABAergic system and a dysregulation of translocator protein $18 \mathrm{kDa}$ (TSPO). Etifoxine is an anxiolytic compound that belongs to the benzoxazine family. It potentiates GABAergic neurotransmission, either through a positive allosteric effect or indirectly, involving the activation of TSPO that leads to an increase in neurosteroids synthesis. In several models of peripheral nerve injury, etifoxine has been demonstrated to display potent regenerative and anti-inflammatory properties and to promote functional recovery. Prior study also showed etifoxine efficacy in reducing brain edema in rats. In light of these positive results, we used a rat model of TBI to explore etifoxine treatment effects in a central nervous system injury, from functional outcomes to the underlying mechanisms.

Methods: Male Sprague-Dawley rats received contusion $(n=18)$ or sham $(n=19)$ injuries centered laterally to bregma over the left sensorimotor cortex. They were treated with etifoxine $(50 \mathrm{mg} / \mathrm{kg}$, i.p.) or its vehicle $30 \mathrm{~min}$ following injury and every day during 7 days. Rats underwent behavioral testing to assess sensorimotor function. In another experiment, injured rats $(n=10)$ or sham rats $(n=10)$ received etifoxine (EFX) $(50 \mathrm{mg} / \mathrm{kg}$, i.p.) or its vehicle 30 min post-surgery. Brains were then dissected for analysis of neuroinflammation markers, glial activation, and neuronal degeneration.
\end{abstract}

Results: Brain-injured rats exhibited significant sensorimotor function deficits compared to sham-injured rats in the bilateral tactile adhesive removal test, the beam walking test, and the limb-use asymmetry test. After 2 days of etifoxine treatment, behavioral impairments were significantly reduced. Etifoxine treatment reduced proinflammatory cytokines levels without affecting anti-inflammatory cytokines levels in injured rats, reduced macrophages and glial activation, and reduced neuronal degeneration.

Conclusions: Our results showed that post-injury treatment with etifoxine improved functional recovery and reduced neuroinflammation in a rat model of TBI. These findings suggest that etifoxine may have a therapeutic potential in the treatment of TBI.

Keywords: Traumatic brain injury, Etifoxine, Neuroinflammation, TSPO, Neurosteroids, Functional recovery, Cytokines, Astrogliosis, Neuronal degeneration, Microglia

(Continued on next page)

\footnotetext{
* Correspondence: e.simonobrien@biocodex.fr

Pharmacology Department, Biocodex, Chemin d'Armancourt, 60200

Compiègne, France
} 


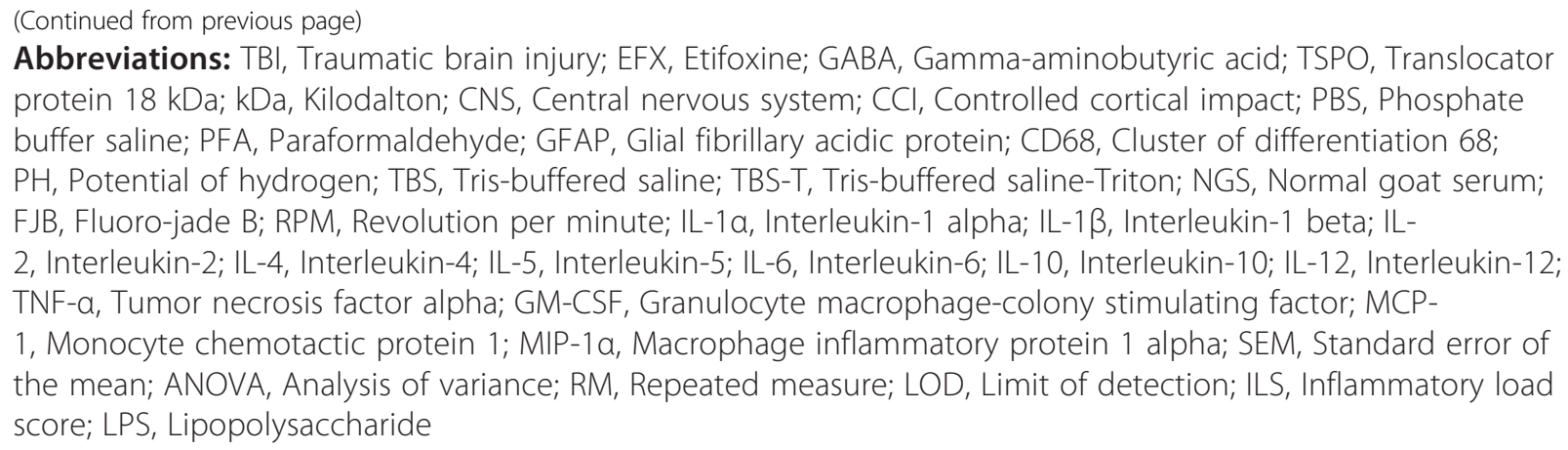

\section{Background}

Traumatic brain injury (TBI) is a leading cause of mortality and morbidity and can result in long-term physical, behavioral, and cognitive deficits. These deficits are due to both primary and secondary injuries. The primary injury occurs at the moment of TBI impact, with disruption of blood brain barrier and blood vessels that contribute to edema formation [1]. This primary injury precedes several downstream events contributing to secondary injury cascade of cellular, molecular, and metabolic pathological events, such as activation of brain-resident microglia and astrocytes, production of cytokines and chemokines, or recruitment of peripheral immune cells into the brain [2-4]. TBI is also followed by a profound reorganization of the GABAergic system and a dysregulation of the mitochondrial $18 \mathrm{kDa}$ translocator protein (TSPO) levels [5]. These events may lead to acute and chronic cell death and contribute to functional impairments [6,7]. The onset of secondary injuries can be delayed for minutes to hours and persist for weeks to months $[8,9]$.

Etifoxine (EFX) ((2-ethylamino-6-chloro-4-methyl-4phenyl-4H-3,1-benzoxazine hydrochloride) is an anxiolytic compound that belongs to the benzoxazine family. Its anxiolytic and anticonvulsant properties have been shown in rodents $[10,11]$, and it is effective in the treatment of adjustment disorders with anxiety in humans [12-14]. Etifoxine binds directly to the $\mathrm{GABA}_{\mathrm{A}}$ receptor, acting as a positive allosteric modulator, thus potentiating GABAergic synaptic transmission [10, 15-17]. EFX also activates TSPO [18] which plays an important role for the synthesis of neurosteroids [19]. Etifoxine was indeed shown to inhibit the binding of the selective TSPO ligand $[3 \mathrm{H}] \mathrm{PK} 11195$. In addition, i.p. administration of EFX increased plasma and brain concentrations of progesterone, pregnenolone, $5 \alpha$-dihydroprogesterone, and allopregnanolone $[18,20]$. The formation of these neurosteroids might result in a brain region-specific enhancement of GABAergic neuronal inhibition [21]. In the central nervous system (CNS), TSPO is generally expressed in both microglia and in reactive astrocytes [22]. Although TSPO level in the brain is low, it increases after brain injury $[5,22]$ and is thus a marker of brain injury and repair [5, 23-25]. Emerging evidence suggests that administration of TSPO selective ligands may be a therapeutic tool in the treatment of inflammatory conditions [26] and might be neuroprotective [27-29]. Some studies showed that EFX displays potent regenerative and anti-inflammatory properties, promotes functional recovery in experimental models of traumatic peripheral nerve injury, and reduces brain edema in rats [30-32]. To investigate further the potential neuroprotective and anti-inflammatory effect of EFX, we tested this compound in a model of TBI induced by controlled cortical impact (CCI) [33, 34] in male adult rats. This model has numerous advantages such as the possibility to control deformation parameters, including duration, depth, and velocity of impact.

\section{Methods}

\section{Animal subjects}

All experiments were performed on male SpragueDawley rats weighing $250-300 \mathrm{~g}$ at the time of injury (Janvier laboratories, Le Genest Saint Isle, France). Rats were group-housed with ad libitum access to food and water in a temperature-controlled $\left(22 \pm 2{ }^{\circ} \mathrm{C}\right)$ and humidity-controlled ( $55 \pm 10 \%)$ environment. Lights were on a 12-h light/dark cycle (lights on at 7:00 a.m). Experiments were carried out in strict accordance with the European Community regulations for animal use in research (2010/63/EU directive), and all protocols were approved by the Local Ethical Committee (C2EAn $\left.{ }^{\circ} 72\right)$.

\section{Drugs}

Etifoxine (batches 562 and 653, Biocodex, Gentilly, France) was suspended in $0.9 \%$ saline containing $1 \%$ Tween 80 ( $\mathrm{vol} / \mathrm{vol})$. This compound and its vehicle were administered intraperitoneally (i.p.) in a volume of $5 \mathrm{~mL} / \mathrm{kg}$ of bodyweight.

\section{Traumatic brain injury procedure}

Rats were subjected to TBI using a controlled cortical impactor (Impact One ${ }^{\mathrm{Tm}}$, Leica Microsystem, Illinois, 
USA). Following deep anesthesia using isoflurane (induction $4 \%$, maintenance $2 \%$ ), rats were stabilized in a stereotaxic frame (David Kopf Instruments, California, USA) and placed on a heated pad. After exposing the skull, a 4-mm diameter circular craniotomy was performed using an electronic hand drill. Rats received contusion injury centered $2 \mathrm{~mm}$ lateral to the bregma over the left sensorimotor cortex with a velocity of $3.0 \mathrm{~m} / \mathrm{s}$, a depth of $1.5 \mathrm{~mm}$, and a duration of $0.5 \mathrm{~s}$ [34-38]. The impactor tip was angled $8^{\circ}$ vertically to maintain a perpendicular position in reference to the tangential plane of the brain convexity at the impact surface. A small quantity of saline solution at room temperature was directed at the site of drilling to prevent thermal injury [39]. After the impact, the scalp was sutured closed. Sham animals received craniotomy but no impact from the CCI device. All animals were closely monitored post-operatively with weight and health surveillance.

\section{Experimental design}

This study was divided in two parts. In the first part, we wanted to assess the effects of EFX treatment on sensorimotor deficits induced by CCI in rats. To this aim, we administered EFX at the anxiolytic-like effective dose of $50 \mathrm{mg} / \mathrm{kg}$, i.p. [10], or its vehicle, $30 \mathrm{~min}$ after TBI ( $n=10$ for TBI-vehicle group, $n=8$ for TBI-EFX group) or sham surgery $(n=9$ for sham-vehicle group, $n=10$ for sham-EFX group), then daily after behavioral testing during 1 week. The second part consisted in studying the effects of EFX treatment on neuroinflammation markers induced by TBI in our rat model ( $n=5$ /group). The critical time-points to study were chosen based on the behavioral results.

\section{Effects of EFX treatment on sensorimotor performances}

Bilateral tactile adhesive removal test This test was performed on days 2, 5, and 7 post-CCI in order to test the forepaw sensitivity as well as motor impairments [40-42]. Each rat was placed into a transparent box $(426 \times 266 \times 185 \mathrm{~mm})$ during a habituation period of $60 \mathrm{~s}$. Thereafter, two adhesive labels $(13 \mathrm{~mm}$ diameter, Tough-Spots ${ }^{\oplus}$ ) were applied with equal pressure on each animal's wrist as bilateral tactile stimuli. The time to contact each paw ("contact time") and to remove ("removal time") the adhesive labels were measured with a maximum of $120 \mathrm{~s}$. The contact time is defined as the time it takes for the rat to react to the presence of the adhesive labels. The rat may either shake its paw and/or bring it to its mouth. There were 5 days of pre-testing in order to obtain an optimal level of performance, to limit inter-individual variations and asymmetries. A trial ended when the rat removed both labels or after $3 \mathrm{~min}$.
Tapered beam walking test Motor performance and coordination can be measured with the tapered beam walking test [43]. Prior to surgery, all animals were trained to traverse a $165-\mathrm{cm}$ long elevated, tapering beam with a $2-\mathrm{cm}$ ledge in order to go in their home cage (Campden Instruments, Lafayette, IN, USA) (two trials per day for 5 days). Criterion performance was assessed as the ability to traverse the beam five times in a row without stopping. The day of the test (on days 2, 5 , and 7 post-CCI), animals are videotaped while traversing the beam (four trials), and performance was rated on the percentage of contralateral hind limb faults (calculated by dividing the number of foot faults by the total number of steps and multiplying by 100) [44, 45].

Limb-use asymmetry test This procedure was adapted from Schallert et al. [46]. Injured animals use less often their contralateral limbs (injured site) to balance themselves while rearing along the wall of the cylinder [47]. Each animal was placed in a transparent glass cylinder (20 cm diameter and $38 \mathrm{~cm}$ height), and its spontaneous activity to explore the vertical surface with its forelimbs was analyzed by videotaping during $3 \mathrm{~min}$. A mirror was placed behind the cylinder at an angle to allow the observer to record forelimb movements when the animal was turned away from the camera. Rats used either both forelimbs or a single one for an exploration. The number of both, right only, or left only explorations was counted. The laterality score was computed as follows: (number of left only-number of right only)/(number of left only + number of right only + number of both). Rats with unilateral lesion prefer to use the limb ipsilateral to the lesion.

\section{Effects of EFX treatment on neuroinflammation}

GFAP and CD68 immunostaining Forty-height hours after surgery (24 h after the second and last EFX administration), animals were deeply anesthetized with sodium pentobarbital $(80 \mathrm{mg} / \mathrm{kg})$ and perfused intracardially with phosphate buffer saline (PBS) at room temperature followed by ice-cold $4 \%$ paraformaldehyde (PFA). Brains were removed and post-fixed in the same fixative for $24 \mathrm{~h}$ and soaked in $30 \%$ sucrose solutions. Brains were then frozen and sectioned $(50 \mu \mathrm{m})$ using a cryostat (Leica CM 1850, Leica, Wetzlar, Germany). Free-floating sections were immunostained for glial fibrillary acidic protein (GFAP), a marker of astrocytic activation, and cluster of differentiation 68 (CD68), a marker of macrophages and activated microglia, as follow: slides were rinsed in tris-buffered saline (TBS, $\mathrm{pH} 7.4$ ), then incubated for 30 min with hydrogen peroxide to quench endogenous peroxidases, rinsed in TBS-Triton (TBS-T), and pre-incubated $60 \mathrm{~min}$ with $5 \%$ blocking serum in 
TBS-T. Tissue sections were then incubated overnight at $4{ }^{\circ} \mathrm{C}$ with a rabbit anti-GFAP antibody (Abcam, Cambridge, UK) diluted (1:5000) or a mouse anti-CD68 antibody (Bio-Rad Laboratories, Hercules, CA, USA) diluted (1:200) in TBS-T containing $2 \%$ normal goat serum (NGS). Slides were rinsed in TBS-T and incubated $30 \mathrm{~min}$ with a goat anti-rabbit biotinylated antibody (Abcam) diluted (1:500) or a goat anti-mouse biotinylated antibody (Abcam) diluted (1:500) in TBS-T and $2 \%$ NGS. Slides were then rinsed and processed by using the Vectastain ABC Elite kit (Vector Laboratories, Burlingame, CA, USA) and stained with diaminobenzidine and hydrogen peroxide.

Fluoro-jade B staining Fluoro-jade B (FJB) is a fluorescent marker that sensitively and specifically binds to degenerating neurons [48]. Brain sections were first incubated in absolute ethanol during $3 \mathrm{~min}$, then $70 \%$ ethanol during a minute, and rinsed in distilled water. Sections were then incubated in a solution of $0.06 \%$ potassium permanganate for $15 \mathrm{~min}$, rinsed in distilled water for a minute, and incubated in $0.0004 \%$ solution of FJB (Interchim, Montluçon, France) for $30 \mathrm{~min}$.

Image analysis Slices were mounted on coverslips with Neo-Mount ${ }^{\circ}$ mounting medium (VWR, Fontenay-sousBois, France) before analysis with an optical microscope (Leica DM 4000, Leica) coupled to a camera (Sony XCD-U100CR, Sony, Tokyo, Japan) and to an acquisition system (Archimed, Microvision Instruments, Evry, France). All images were acquired using the same light level by using a 20x (for CD68 and GFAP immunostaining) or 10x (for FJB staining) objective lens. The number of CD68+ cells was counted manually: three sections from each rat were selected for analysis. One section was at the epicenter of the impact (bregma $0 \mathrm{~mm}$ ) while the other two were either $300 \mu \mathrm{m}$ rostral or caudal to the epicenter. For GFAP expression, 12 non-consecutive sections were immunostained, representing the area of the lesion (approximately bregma $+1.8 \mathrm{~mm}$ to bregma $-1.8 \mathrm{~mm}$ ) and quantified. Sections were digitized as grayscale images after background subtraction for quantification of intensity (Image J, NIH, version 1.46). For FJB staining, all sections were observed and photographed with blue excitation light $(480 \mathrm{~nm})$. The number of FJB+ cells was counted manually in the contusion margin along the cortex. For all analysis, brain sections from stereotaxically corresponding regions were used in sham-treated rats.

Cytokine immunoassay Cytokine multiplex assay was performed on the cerebral cortex. Brain tissues were harvested and frozen 6 or $12 \mathrm{~h}$ post-injury separately from each hemisphere. Tissues were then homogenized in a lysis buffer (RIPA buffer, Abcam) containing protease inhibitor cocktail (Pierce ${ }^{\mathrm{Tm}}$ protease inhibitor, Thermo Fisher Scientific, Waltham, MA, USA). Tissue homogenates were centrifuged at 13,000 rpm for $20 \mathrm{~min}$ at $4{ }^{\circ} \mathrm{C}$. Supernatants were transferred to new tubes and used for analysis. All assays were performed according to the manufacturer's instructions, in duplicates, and without adjustments to the recommended standard curve dilution. The concentration of 12 cytokines/chemokines (IL-1 $\alpha$, IL-1 $\beta$, IL-2, IL-4, IL-5, IL-6, IL-10, IL-12, TNF- $\alpha$, GM-CSF, MCP-1, and MIP-1 $\alpha$ ) was determinate by Bio-Plex Pro $^{\text {ma }}$ rat cytokine assays (catalog number: 171-K1001M, Bio-Rad Laboratories, Hercules, CA, USA) in $500 \mu \mathrm{g}$ of total protein of brain cortices homogenates (Bradford assay, Bio-Rad Laboratories). Briefly, magnetic beads conjugated with cytokine antibodies were loaded into the wells of a 96-well plate. After washing, standards and samples were added into wells and incubated for $60 \mathrm{~min}$ at room temperature on a shaking platform. The beads were washed and incubated with biotinylated detection antibody for $30 \mathrm{~min}$ at room temperature. Following the removal of excessive detection antibodies, streptavidin-phycoerythrin conjugate compound was added and allowed to incubate for $10 \mathrm{~min}$ at room temperature. Cytokines concentrations were determined by Bio-Plex Manager ${ }^{\mathrm{Tx}}$ MP software version 6.1 and calculated against the standard curve. Samples with out of range (low) levels were assigned the limit of detection (LOD) (Table 1) of the assay for analysis purposes. The intra-assay percentage coefficient of variation $(\mathrm{CV})$ ranged from 1.28 to $9.48 \%$.

Statistical analysis All data are presented as mean \pm standard error of the mean (SEM) and were submitted to a square root transformation to meet the requirements of normality if necessary. Behavioral data were analyzed using three two-way analysis of variance

Table 1 Limit of detection (LOD) of the Bio-Plex Pro ${ }^{\mathrm{TM}}$ rat cytokine assays (Bio-Rad Laboratories, Hercules, CA, USA)

\begin{tabular}{ll}
\hline Targets & $\begin{array}{l}\text { Assay sensitivity, pg/mL, LOD } \\
\text { (limit of detection) }\end{array}$ \\
\hline IL-1a & 1 \\
IL-1 $\beta$ & 2 \\
IL-2 & 3 \\
IL-4 & 1 \\
IL-5 & 6 \\
IL-6 & 10 \\
IL-12 & 0.7 \\
TNF-a & 3 \\
GM-CSF & 0.6 \\
MIP-1a & 12 \\
MCP-1 & 4 \\
\hline
\end{tabular}


(ANOVA) with repeated measures (RM) with post hoc Tukey's multiple comparison test. The first ANOVA consists in studying the effects of TBI on sensorimotor performances (comparison between sham-vehicle and TBI-vehicle groups) with two factors: time in RM and injury. Then, we did the same type of analysis for the effects of EFX treatment on the TBI group and on the sham-operated one. Significant main or interaction effects were followed by Tukey post hoc analyses. Biochemical data were analyzed using a two-way ANOVA (TBI or Sham) $\mathrm{x}$ (EFX or Vehicle) with post hoc Tukey's multiple comparison test. Inflammatory load score (ILS) was calculated for each rats as follow: animals with the lowest values for a given cytokine $(\leq 25$ th percentile) were assigned a 1 , between the 26th and the 50th percentile animals were assigned a 2 , between the 51th percentile and the 75th percentile animals were assigned a 3 , and for the largest values $(\geq 76$ th percentile), animals were assigned a 4 . An ILS for each rat was calculated by summing the quartile rank for each of the pro-inflammatory cytokines. All statistical analyses were performed using SigmaStat ${ }^{\bullet}$ software v 3.5 (Systat Software Inc., San Jose, California, USA). Significance was set at $p<.05$.

\section{Results}

Etifoxine improves adhesive removal task at 2 days post-CCI

Results showed that before surgery, all groups of rats felt the presence of the adhesive stuck on their wrists very quickly (less than $1 \mathrm{~s}$ for each animal). Statistical analyses (two-way RM ANOVA) revealed no significant effect of the injury factor $\left(F_{1}, 18=3.718, p=0.071\right)$, a significant effect of time $\left(F_{3,54}=10.873, p<0.001\right)$ and a significant interaction $\left(F_{3,54}=3.441, p=0.023\right)$. Post hoc analyses showed that 2 days post-surgery, TBIvehicle-treated rats needed significantly more time to feel the presence of the adhesive compared to presurgery $(53.3 \pm 16.5 \mathrm{~s})(p<0,001)$. Sham-operated animals did not present any deficit. In the injured group, two-way RM ANOVA showed no effect of treatment $\left(F_{1,16}=2.208, p=0.157\right)$, a significant effect of time $\left(F_{3}, 48=12.826, p<0.001\right)$ and no significant interaction $\left(F_{3}, 48=1.954, p=0.133\right)$. Post hoc analyses showed that EFX treatment significantly reduced the contact time in injured animals 2 days post-surgery $(23.7 \pm 9.7$ s vs. $53.3 \pm 16.5$ s, $p=0.006)$. No significant differences were observed on day +5 and day +7 postsurgery in any groups (Fig. 1).

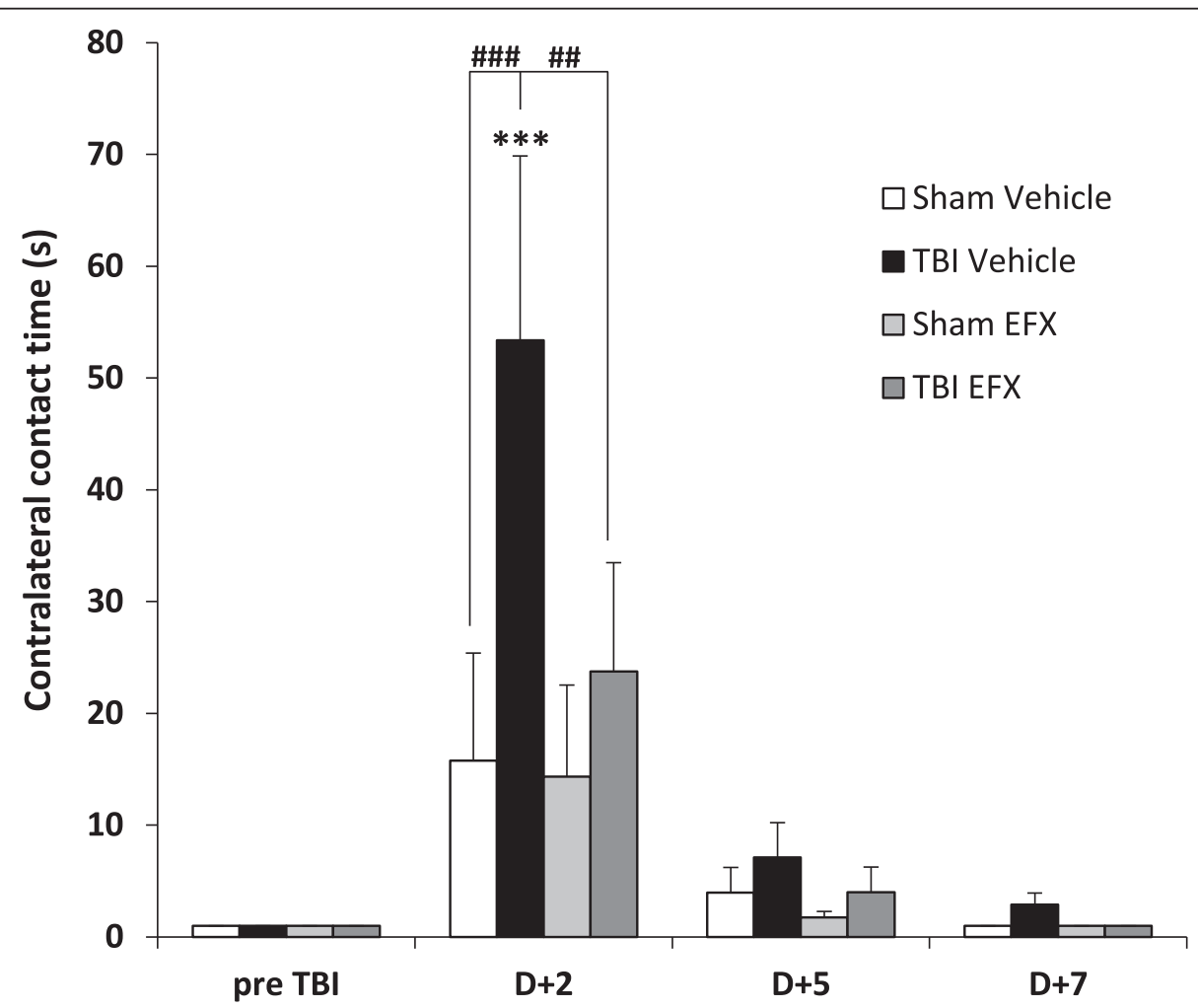

Fig. 1 Bilateral adhesive removal test. Mean (+SEM) time to contact the contralateral adhesive in sham-vehicle $(n=9)$, TBI-vehicle $(n=10)$, shamEFX $(n=10)$, and TBI-EFX $(n=8)$ groups. EFX treatment significantly improved the time to contact on day 2 post-CCl compared with vehicle treatment in TBl animals $(\# \#<0.01) .{ }^{* * *} p<0.001$ compared to pre-TBI; ${ }^{\# \#} p<0.001$ and ${ }^{\# \#} p<0.01$ compared to TBI-vehicle 
Mean removal time was $16.72 \pm 1.85 \mathrm{~s}$ in all groups before surgery. Two-way RM ANOVA revealed a main effect of injury $\left(F_{1,18}=6.150, p=0.024\right)$, a main effect of time $\left(F_{3,54}=10.747, p<0.001\right)$ and no significant interaction $\left(F_{3,54}=2.602, p=0.062\right)$. Post hoc Tukey's analyses revealed that injured-vehicle-treated animals spent significantly more time to remove the adhesive than sham-vehicle-treated animals at day 2 post-surgery $(83.4 \pm 16.2 \mathrm{~s}$ vs. $35.9 \pm 12.6 \mathrm{~s}, p<0.001)$. Two-way RM ANOVA showed no significant treatment effect in the injured group $\left(F_{1,16}=2.744, p=0.117\right)$ but a significant effect of time $\left(F_{3}, 48=14.258, p<0.001\right)$ and no significant interaction $\left(F_{3,48}=1.035, p=0.386\right)$. Post hoc analyses showed that treatment with EFX significantly reduced the time to remove the adhesive in injured animals $(52.6 \pm 12.9$ s vs. $83.4 \pm 13.2 \mathrm{~s}, p=0.043)$. No significant differences were observed on day +5 and day + 7 post-surgery in any groups (Fig. 2).

\section{Etifoxine improves beam walk task at 2 days post-CCI}

Two-way repeated measures ANOVA revealed that exposure to $\mathrm{CCI}$ injury resulted in a main significant effect $\left(F_{1,18}=10.014, p=0.005\right)$, a significant main effect of time $\left(F_{3,54}=10.624, p<0.001\right)$ and a significant interaction $\left(F_{3}, 54=9.084, p<0.001\right)$. Post hoc analyses showed that 2 days post-injury, TBI-vehicle-treated animals made more foot faults in comparison with sham-vehicle animals $(39.8 \pm 8.9$ vs. $4.7 \pm 2.5 \%, p<$ $0.001)$. At day +5 and day +7 post-surgery, this impairment is not observed anymore. In the injured groups, two-way RM ANOVA showed no effect of treatment $\left(F_{1}\right.$, $16=1.296, p=0.272$ ), a significant main effect of time $\left(F_{3,48}=14.666, p<0.001\right)$ and no significant interaction $\left(\mathrm{F}_{3,48}=1.217, p=0.314\right)$. Post hoc analyses showed that two days of EFX treatment significantly reduced the percentage of contralateral hind limb faults in TBI-EFX animals in comparison with TBI-vehicle-treated animals $(25.3 \pm 9.2$ vs. $39.8 \pm 8.9 \%, p=0.039)$ (Fig. 3).

\section{Etifoxine improves limb-use asymmetry test at 2 days post-CCI}

Two-way ANOVA with repeated measures showed a significant effect of injury on rats $\left(F_{1,18}=37.255, p<0.001\right)$, a significant effect of time $\left(F_{3,54}=17.433, p<0.001\right)$ and a significant interaction $\left(F_{3,54}=15.953, p<0.001\right)$. Post hoc analyses indicated that injured-vehicle-treated rats had higher asymmetry scores at day +2 , day +5 , and day +7 post-injury compared with sham-vehicle-treated animals $(p<0.001)$. Two-way RM ANOVA showed a significant main effect of EFX treatment in injured rats $\left(F_{1,16}=\right.$ 7.203, $p=0.016)$, a significant effect of time $\left(F_{3,48}=\right.$ 25.754, $p<0.001)$ and a significant interaction $\left(F_{3,48}=\right.$

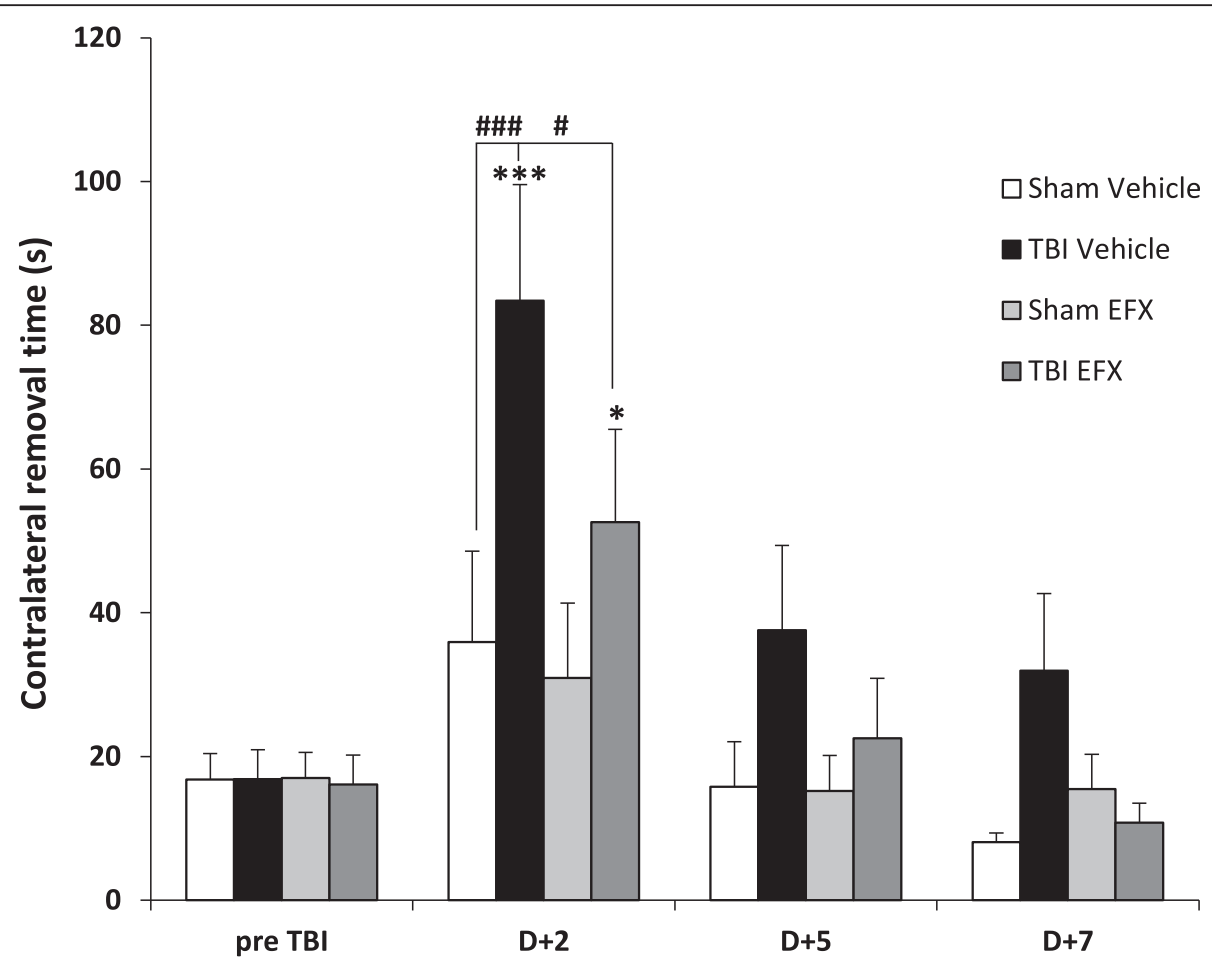

Fig. 2 Bilateral adhesive removal test. Mean (+SEM) time to remove the contralateral adhesive in sham-vehicle $(n=9)$, TBI-vehicle $(n=10)$, sham$\mathrm{EFX}(n=10)$, and TBI-EFX $(n=8)$ groups. EFX treatment significantly improved the time to remove the adhesive on day 2 post-CCl compared with vehicle treatment in TBI animals $\left({ }^{\#} p<0.05\right)$. ${ }^{* *} p<0.001$ and ${ }^{*} p<0.05$ compared to pre-TBl; ${ }^{* \# \#} p<0.001$ and ${ }^{*} p<0.05$ compared to TBI-vehicle 


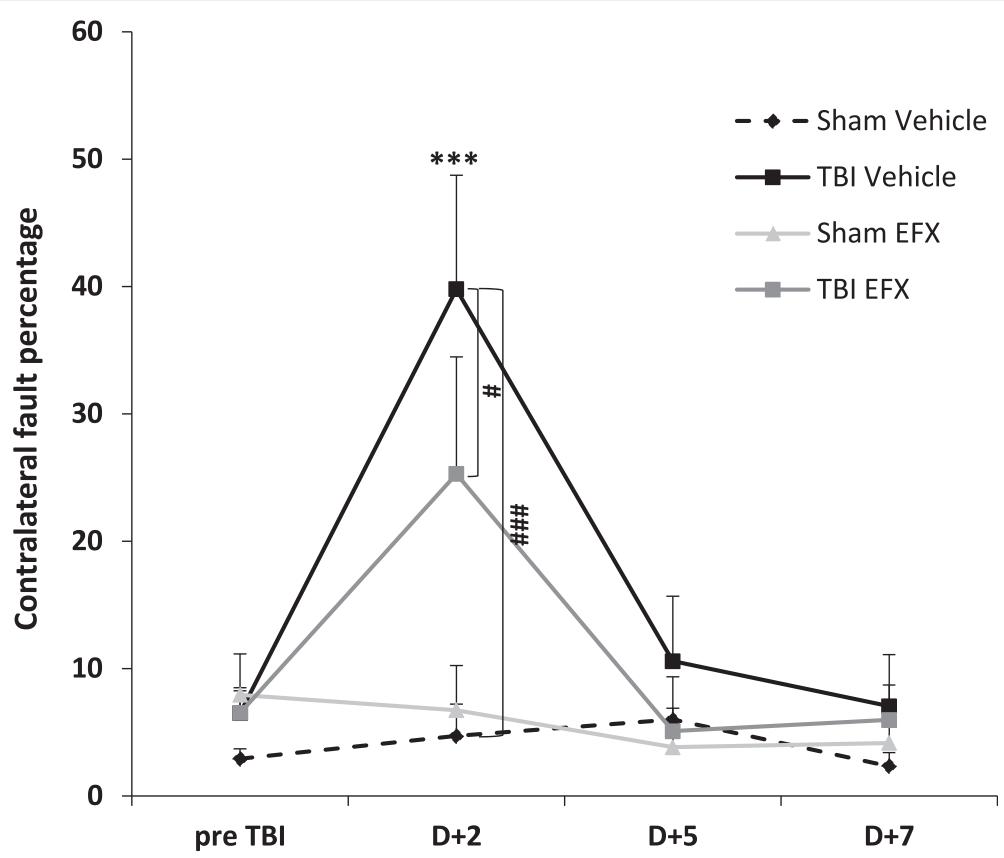

Fig. 3 Tapered beam walking test. Mean (+SEM) percentage of faults with the contralateral hind limb on the beam in sham-vehicle $(n=9)$, TBIvehicle $(n=10)$, sham-EFX $(n=10)$, and TBI-EFX $(n=8)$ groups. Treatment with EFX significantly improved motor performance and coordination on day 2 post-CCl compared to vehicle treatment in TBI animals $\left({ }^{\#} p<0.05\right)$. ${ }^{* *} p<0.001$ compared to pre-TBl; ${ }^{\# \# \#} p<0.001$ and ${ }^{\#} p<0.05$ compared to TBI-vehicle

3.280, $p=0.030)$. Tukey's test showed a significant improvement in limb-use asymmetries in EFX-treated animals compared to vehicle-treated animals 2 days post-injury $(p=0.003)$ and 5 days post-injury $(p=$ 0.017) (Fig. 4).
Etifoxine decreases astrogliosis in the injured cortex at 2 days post-CCI

Activated astrocytes were visualized by immunohistochemistry for GFAP. Two-way ANOVA showed a significant main effect of CCI $\left(F_{1,223}=119.61, p<0.001\right)$, a

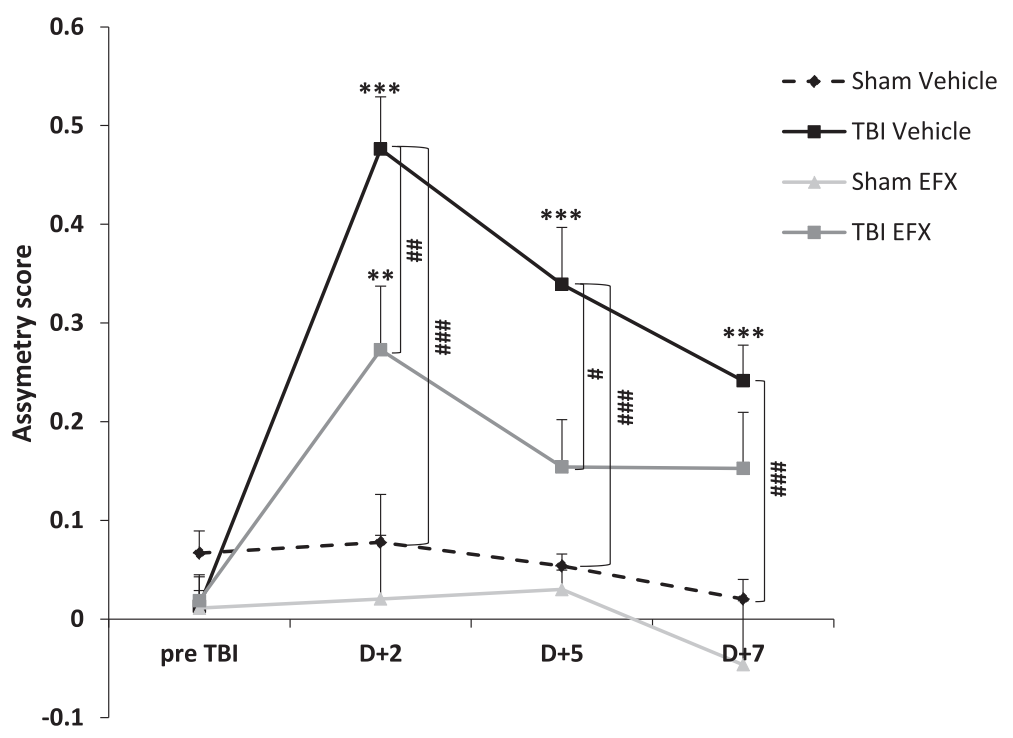

Fig. 4 Limb-use asymmetry test. Mean (+SEM) asymmetry score in sham-vehicle $(n=9)$, TBI-vehicle $(n=10)$, sham-EFX $(n=10)$, and TBI-EFX $(n=8)$ groups. Higher scores indicate a greater use of the unimpaired forelimb. Treatment with EFX significantly improved asymmetry score on day $2\left({ }^{\# \#} p<0.01\right)$ and day $5\left({ }^{\#} p<0.05\right)$ post $-\mathrm{CCl}$ compared to vehicle treatment in TBI animals. ${ }^{* *} p<0.001$ and ${ }^{* *} p<0.01$ compared to pre-TBl; ${ }^{\# \# \#} p<0.001, \# p<0.01$, and ${ }^{\#} p<0.05$ compared to TBI-vehicle 
significant main effect of EFX treatment $\left(F_{1,223}=21.34\right.$, $p<0.001)$, and no interaction $\left(F_{1,223}=0.035, p=0.851\right)$. Post hoc Tukey's analyses showed that immunostaining for GFAP revealed evidence of a reactive astrogliosis in regions of the cortex underlying the impact site at day + 2 post-surgery $(21.3 \pm 1.6 \%$ in the TBI-vehicle group vs. $6.8 \pm 1.2 \%$ in the sham-vehicle group, $p<0.001)$. EFX treatment significantly reduced GFAP immunoreactivity in injured animals $(15.0 \pm 1.3 \%$ in the TBI-EFX group vs. $21.3 \pm 1.6 \%$ in the TBI-vehicle group, $p=0.001)$ as well as in sham animals $(1.1 \pm 0.3 \%$ in the sham-EFX group vs. $6.8 \pm 1.2 \%$ in the sham-vehicle group, $p=$ 0.001) (Fig. 5). Figure 5 shows the typical star-like hypertrophied aspect of astrocytes in response to injury which is a characteristic marker of the inflammatory cascade induced by CNS trauma and which contributes to later pathology.

Etifoxine reduces activated microglia/macrophage density in the injured cortex at 2 days post-CCl

Blood-borne and resident macrophages/activated microglia can be visualized by anti-CD68 staining (Fig. 6).
Two-way ANOVA revealed a significant main effect of surgery $\left(F_{1,65}=24.87, p<0.001\right)$, a significant main effect of EFX treatment $\left(F_{1,65}=13.09, p<0.001\right)$, and no interaction $\left(F_{1,65}=1.099 ; p=0.298\right)$. As shown in Fig. 6 , post hoc analyses showed a significant increase in CD68 + cells in the cortical contusion margin of rats 2 days post-CCI $(584 \pm 100$ for TBI-vehicle group vs. $194 \pm 61$ for sham-vehicle group, $p<0.001)$. A significant reduction in the density of activated microglia/macrophages was observed in EFX-treated rats compared with vehicle controls $(282 \pm 33$ in the TBI-EFX group vs. $584 \pm$ 100 in the TBI-vehicle group, $p<0.001)$. No positive staining was observed in the hemisphere contralateral to the impact site.

\section{Etifoxine reduces neuronal degeneration in the injured cortex at 2 days post-CCI}

Statistical analyses revealed a significant main effect of surgery $\left(F_{1,297}=51.439, p<0.001\right)$, a significant main effect of EFX treatment $\left(F_{1,297}=20.042, p<0.001\right)$, and a significant interaction $\left(F_{1,297}=10.521, p=0.001\right)$. Post hoc analyses showed that $\mathrm{FJB}+$ cells with neuronal

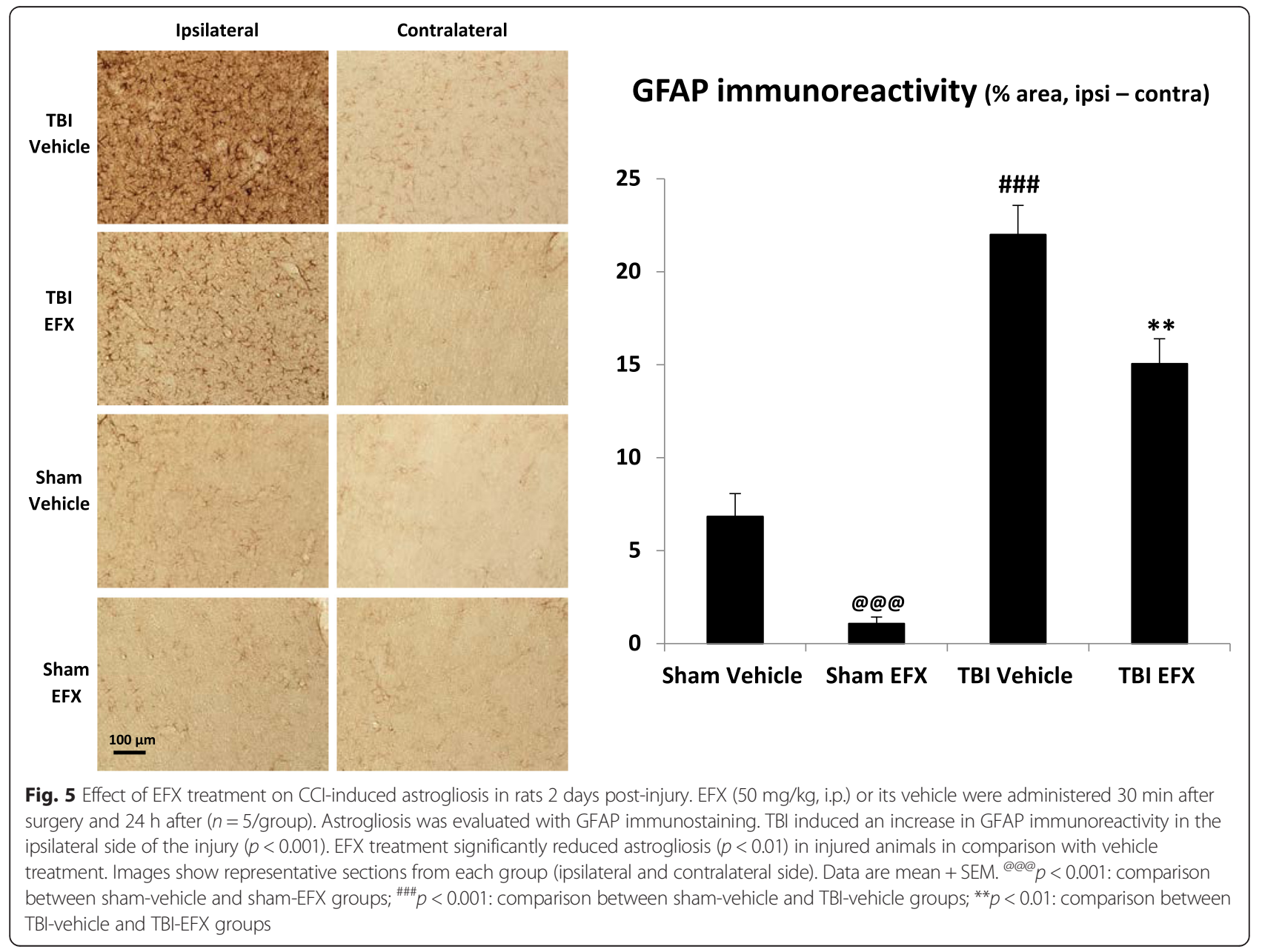




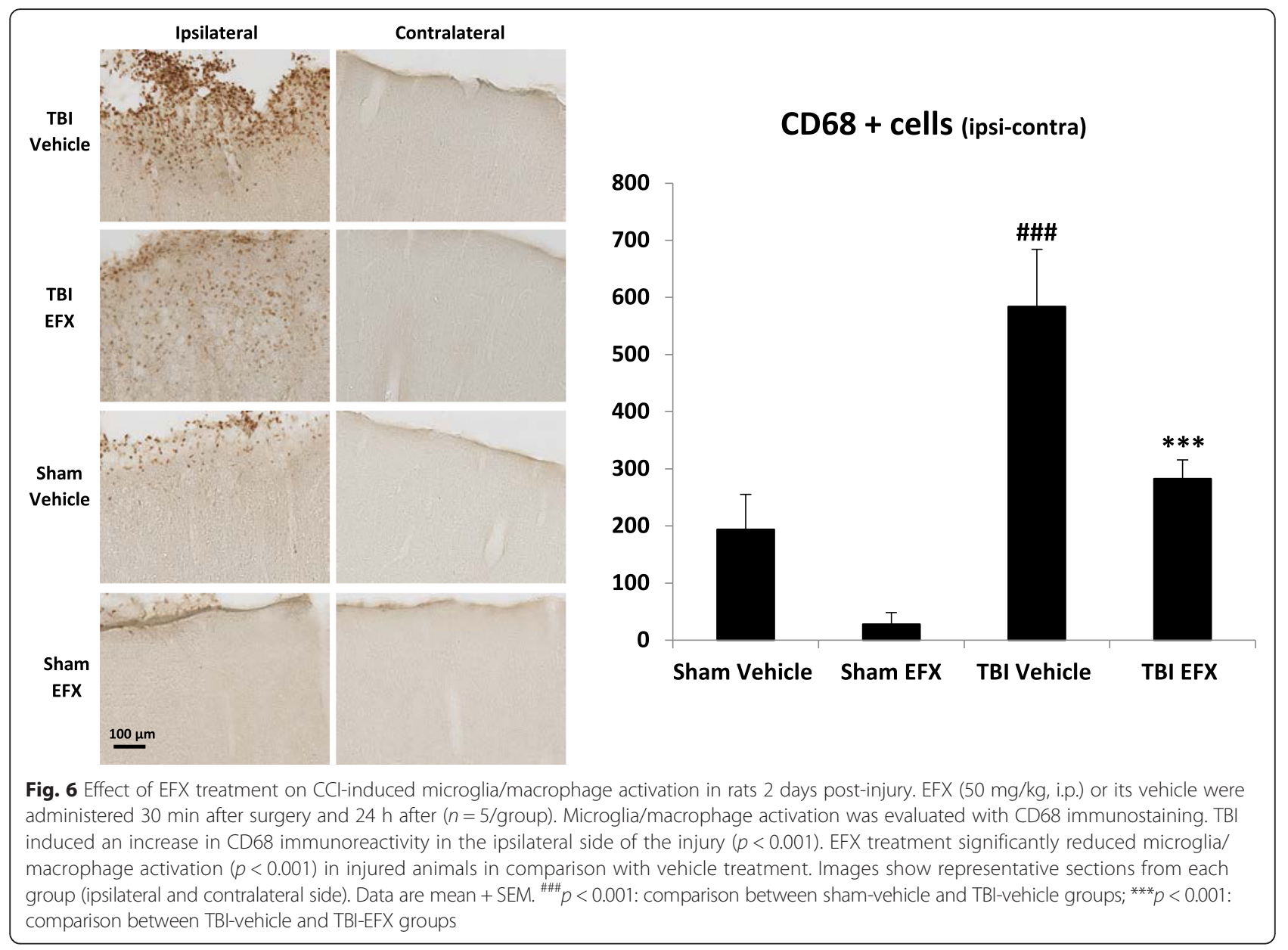

morphology were evident 2 days after CCI in the cortical contusion margin but not in the contralateral hemisphere. Ipsilateral minus contralateral $\mathrm{FJB}+$ cells counting showed that neuronal degeneration was significantly more important in TBI-vehicle group compared with sham-vehicle group (98 \pm 11 for TBI-vehicle group vs. 8 \pm 3 for sham-vehicle group, $p<0.001)$. Etifoxine treatment significantly reduced the number of $\mathrm{FJB}+$ cells in CCI rats compared with vehicle treatment $(26 \pm 5$ for TBI-EFX group vs. $98 \pm 11$ for TBI-vehicle group, $p<$ 0.001) (Fig. 7).

\section{Etifoxine reduces cortical level of pro-inflammatory cytokines}

Different studies showed that the temporal change of several inflammatory cytokines peaked at $6 \mathrm{~h}$ after CCI $[3,49]$. We therefore selected this time-point for evaluating EFX treatment on cytokine/chemokine expression. There are no differences within contralateral sites of injury between groups. Two-way ANOVA revealed statistical differences for four pro-inflammatory cytokines, IL- $1 \alpha$, IL- $1 \beta$, IL- 6 , and TNF- $\alpha$, and two chemokines: MCP-1 and MIP-1 $\alpha$. Post hoc testing showed that there was a significant increase in IL- $1 \alpha$, IL-1 $\beta$, IL-6, TNF- $\alpha$, MCP-1, and MIP-1 $\alpha$ levels in the ipsilateral cortices to the injury site of TBI-vehicle-treated group in comparison with sham-vehicle-treated animals $(p<0.001)$. Statistical analyses also showed that EFX treatment significantly reduced this increase in pro-inflammatory cytokines and chemokines levels in the injured group compared to vehicle treatment $(p<0.001$ for IL- $1 \alpha$, IL-1 $\beta$, IL- 6 , and TNF$\alpha, p<0.05$ for MCP-1 and MIP-1 $\alpha$ ). Data are summarized in Table 2. Because multiple testing across the analytes may not be fully accounted for by multiple test correction within each analyte, resulting in type I errors, we have also performed an inflammatory load score (ILS) analysis (Table 3). Two-way ANOVA revealed an overall effect of TBI on inflammation $\left(F_{1,15}=15.46, p=0.001\right)$, an overall effect of EFX treatment $\left(F_{1,15}=11.50, p=0.004\right)$ on ILS, and no interaction $\left(F_{1,15}=3.584, p=0.078\right)$. Post hoc analysis showed that injured animals have a higher ILS compared to sham animals $(p<0.001)$ and that EFX treatment significantly reduced ILS in injured animals $(p=0.003)$ (see Table 3). We also tested the levels of proinflammatory cytokines IL- $1 \alpha$, IL- $1 \beta$, IL- 6 , and TNF- $\alpha$ $12 \mathrm{~h}$ after surgery in order to study their evolution of 


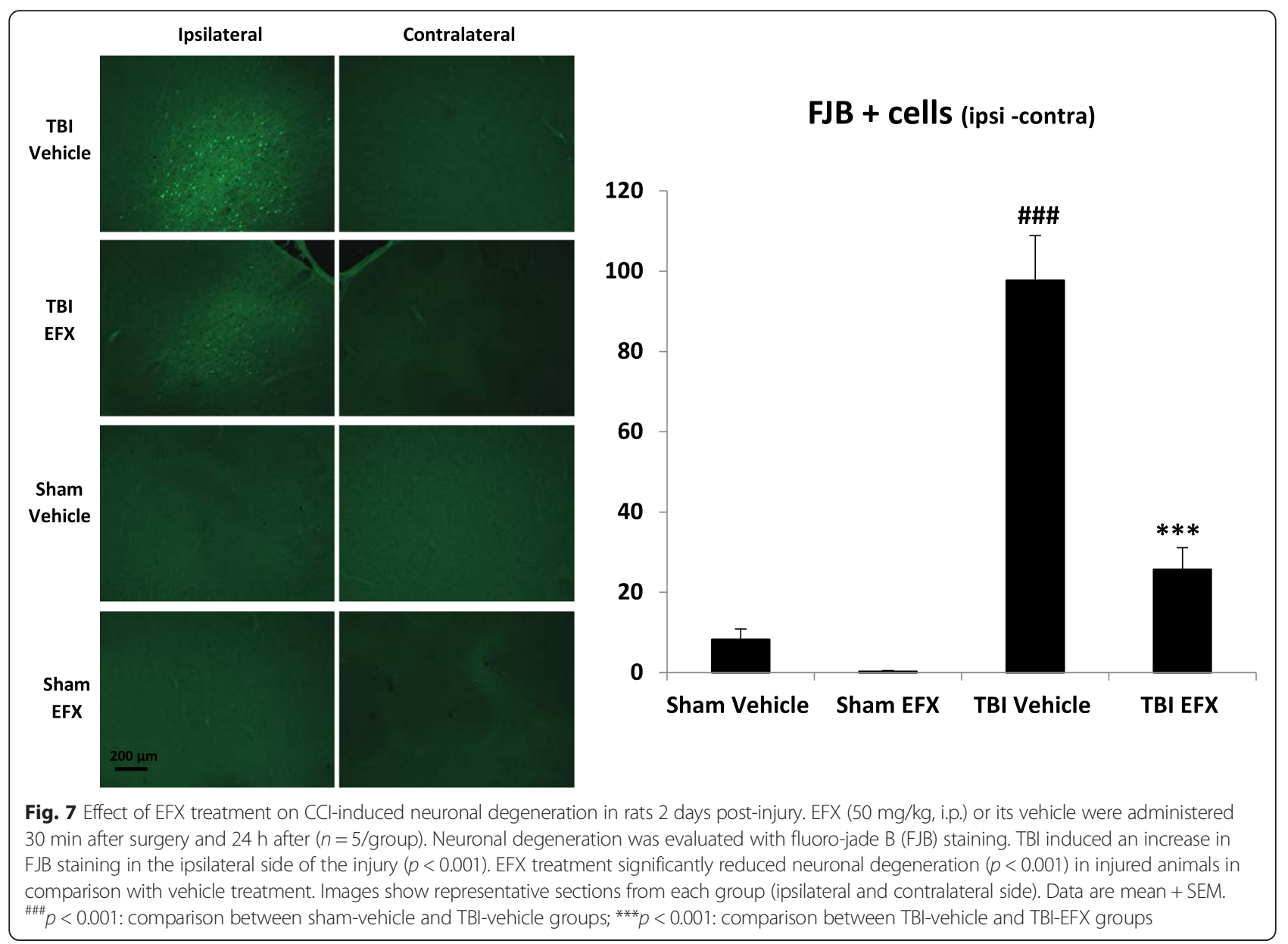

expression. At $6 \mathrm{~h}$ time-point, the profound increase in pro-inflammatory cytokines associated with trauma was significantly reduced by EFX treatment $(p<0.001)$ compared with vehicle-treated rats to such an extent that these values were not different from those for the $12 \mathrm{~h}$ timepoint (Fig. 8). We did not find any modifications of other tested cytokines in injured animals compared to sham animals (data not shown).

\section{Discussion}

Our results showed that TBI model induced by CCI caused sensorimotor deficits in rats measured in three behavioral tasks: bilateral adhesive removal test, tapered beam walk test, and limb-use asymmetry test. An administration of EFX $30 \mathrm{~min}$ after the injury, followed by a second injection after $24 \mathrm{~h}$, significantly improved functional impairments. This protective effect was associated with reduced neuroinflammation, astrogliosis, and neuronal degeneration.

Following TBI, there is a wide range of cellular and biochemical pathological events resulting in neuron and glial cells death. Among these events, neuroinflammation is characterized by the activation of resident astrocytes and microglia and by the infiltration of leukocytes into the injury site. These events lead to the release of inflammatory cytokines and neurotoxic molecules which contribute to progressive cell death and functional impairments [50].

Our results suggest that EFX may reduce delayed neuronal death that contributes to neurological deficits [51] and promote survival in the injury border zone. This hypothesis is supported by the observations that EFX-treated animals showed fewer degenerative neurons than vehicle-treated rats as evaluated by FJB staining.

Among the different mechanisms underlying delayed neuronal loss, post-traumatic neuroinflammation is a major factor. Activation of microglia is one of the central inflammatory responses after TBI [52]. Recent studies showed that brain inflammation has been associated with polarization of microglia and macrophages (M1 and M2 responses) [53-56]. M1 response is an activation of microglia/macrophages that produces proinflammatory substances such as IL- $1 \beta$, IL- 6 , and TNF- $\alpha$ [56]. The M2 response is induced by anti-inflammatory cytokines such as IL-4 and IL-10 [53]. Inflammation is therefore an important tool for controlling TBI effects 
Table 2 Concentrations of cytokines/chemokines in the injured cortex at $6 \mathrm{~h}$ post-CCl or sham-operation in rats treated with EFX or Vehicle control

\begin{tabular}{|c|c|c|c|c|c|c|c|c|}
\hline Sham-veh & $(\mathrm{pg} / \mathrm{mL})$ & Sham-EFX & $\mathrm{g} / \mathrm{mL})$ & TBI-vehicle & & TBI-EFX (p & & $\begin{array}{l}\text { TBI-vehicle vs. } \\
\text { TBI-EFX }\end{array}$ \\
\hline Ipsilateral & Contralateral & |psilateral & Contralateral & Ipsilateral & Contralateral & Ipsilateral & Contralateral & $\begin{array}{l}\text { \% decrease } \\
\text { (ipsilateral side) }\end{array}$ \\
\hline
\end{tabular}

\begin{tabular}{|c|c|c|c|c|c|c|c|c|c|}
\hline \multicolumn{10}{|c|}{ Pro-inflammatory cytokines } \\
\hline $\mathrm{IL}-1 \mathrm{a}$ & $5.75 \pm 0.87$ & $5.17 \pm 0.22$ & $5.53 \pm 0.81$ & $3.83 \pm 0.88$ & $40.41 \pm 5.14^{* * *}$ & $3.27 \pm 0.63$ & $13.55 \pm 2.65^{* *}$ & $1.32 \pm 0.77$ & 33 \\
\hline$I L-1 \beta$ & $45.14 \pm 2.89$ & $37.68 \pm 2.43$ & $56.58 \pm 9.43$ & $34.77 \pm 3.25$ & $382.88 \pm 64.66^{* * *}$ & $33.98 \pm 1.57$ & $148.97 \pm 25.50^{* *}$ & $29.82 \pm 1.72$ & 30 \\
\hline $\mid \mathrm{L}-2$ & $26.47 \pm 0.75$ & $24.84 \pm 0.70$ & $23.48 \pm 0.50$ & $22.89 \pm 1.57$ & $27.55 \pm 4.42$ & $21.55 \pm 0.62$ & $23.44 \pm 1.64$ & $20.46 \pm 0.64$ & D \\
\hline IL-6 & $2.65 \pm 0.33$ & $1.76 \pm 0.23$ & $14.00 \pm 8.89$ & $3.21 \pm 0.71$ & $150.18 \pm 21.25^{* * *}$ & $4.34 \pm 0.64$ & $41.97 \pm 10.25^{* *}$ & $1.86 \pm 0.51$ & \\
\hline IL-12 & $8.87 \pm 0.29$ & $8.54 \pm 0.38$ & $7.50 \pm 0.24$ & $7.50 \pm 0.95$ & $7.41 \pm 0.26$ & $6.95 \pm 0.38$ & $6.95 \pm 0.20$ & $7.10 \pm 0.20$ & DS \\
\hline TNF- $a$ & $5.34 \pm 0.35$ & $1.30 \pm 0.14$ & $5.93 \pm 0.36$ & $4.48 \pm 0.84$ & $16.34 \pm 1.71^{* * *}$ & $5.24 \pm 0.62$ & $9.91 \pm 1.28^{* *}$ & $5.91 \pm 0.70$ & 60 \\
\hline GM-CSF & $2.49 \pm 0.67$ & $2.24 \pm 0.49$ & $2.06 \pm 0.26$ & $1.52 \pm 0.29$ & $1.20 \pm 0.22$ & $1.15 \pm 0.17$ & $1.07 \pm 0.27$ & $1.36 \pm 0.14$ & $n$ \\
\hline \multicolumn{10}{|c|}{ Anti-inflammatory cytokines } \\
\hline $\mid \mathrm{L}-4$ & $2.86 \pm 0.13$ & $2.50 \pm 0.08$ & $3.20 \pm 0.53$ & $2.85 \pm 0.51$ & $4.19 \pm 0.78$ & $2.54 \pm 0.05$ & $3.65 \pm 0.72$ & $2.32 \pm 0.13$ & \\
\hline $\mid \mathrm{L}-5$ & $11.22 \pm 0.24$ & $10.74 \pm 0.24$ & $7.93 \pm 0.31$ & $6.72 \pm 1.71$ & $9.34 \pm 0.63$ & $9.24 \pm 0.89$ & $9.30 \pm 1.18$ & $9.00 \pm 1.13$ & 113 \\
\hline$\| \mathrm{L}-10$ & $25.99 \pm 1.60$ & $24.13 \pm 1.67$ & $19.94 \pm 2.04$ & $19.66 \pm 4.35$ & $35.29 \pm 4.98$ & $17.52 \pm 2.82$ & $28.48 \pm 2.45$ & $23.12 \pm 0.83$ & $\mathrm{~ns}$ \\
\hline \multicolumn{10}{|c|}{ Macrophage-attracting chemokines } \\
\hline MIP-1a & $1.71 \pm 1.01$ & $0.04 \pm 0.04$ & $2.64 \pm 1.3$ & $0.00 \pm 0.00$ & $90.42 \pm 25.47^{* * *}$ & $0.00 \pm 0.00$ & $36.99 \pm 4.51^{*}$ & $0.24 \pm 0.21$ & 4 \\
\hline MCP-1 & $7.50 \pm 1.97$ & $4.30 \pm 0.63$ & $12.82 \pm 5.16$ & $4.25 \pm 0.64$ & $93.82 \pm 21.66^{* * *}$ & $5.53 \pm 0.97$ & $53.00 \pm 7.45^{*}$ & $6.34 \pm 1.55$ & \\
\hline
\end{tabular}

Six hours post TBI, ipsilateral and contralateral cortices were analyzed with the Bio-Plex Pro ${ }^{\text {Tm }}$ rat cytokine assays for IL-1a, IL-1 $\beta$, IL-2, IL-4, IL-5, IL-6, IL-10, IL-12, TNF-a, GM-CSF, MIP-1a, and MCP-1

Data ( $n=5$ /groups) represents mean \pm SEM. $p<0.05$ or less were considered statistically significant. Two-way analysis of variance was performed, followed by Tukey post hoc test

NS not significant

${ }^{* * *} p<0.001$ : comparison between sham-vehicle and TBI-vehicle groups in the ipsilateral side; ${ }^{* *} p<0.001$ and ${ }^{*} p<0.05$ : comparison between TBI-vehicle and TBIEFX groups in the ipsilateral side

and enhancing recovery after injury. Thus, the suppression of $\mathrm{M} 1$ and/or the up-regulation of $\mathrm{M} 2$ response could be used to prevent secondary injury and promote repair processes in the brain. In a study using male Sprague-Dawley rats, Ansari showed an upregulation of pro-inflammatory cytokines (TNF- $\alpha$, IL-1 $\beta$, and IL-6) expression $6 \mathrm{~h}$ post-CCI and an upregulation of antiinflammatory cytokines such as IL-4 and IL-10 but only $24 \mathrm{~h}$ post-injury [57]. These results support other studies showing that early after injury, M1 predominate over M2 response [54, 58, 59]. These observations are in accordance with our results showing an upregulation of pro-inflammatory cytokines such as TNF- $\alpha$, IL- $1 \alpha$, IL$1 \beta$, and IL- 6 early after injury but no upregulation of anti-inflammatory cytokines such as IL-4 and IL-10 $6 \mathrm{~h}$ post-injury. Pro-inflammatory cytokines secreted by activated microglia also secrete chemokines that recruit additional inflammatory cells to the injury site and free radicals that are cytotoxic to neurons and can contribute to neurodegeneration after TBI $[60,61]$. Elevated levels of pro-inflammatory cytokines have been detected in the serum and cerebrospinal fluid of TBI patients $[62,63]$ and in brain parenchyma of animals with experimental brain injuries [64-67]. The role of these pro-inflammatory cytokines has remained controversial, but several studies showed that suppressing their expression may reduce tissue damage and brain edema and also improve functional consequences [2, 68-78]. We demonstrated that acute administration of EFX significantly reduced TBI-induced up-regulation of proinflammatory cytokines. Since TNF- $\alpha$, IL-1 $\beta$, and IL-6 are major pro-inflammatory cytokines that mediate blood brain barrier disruption, edema, and programmed cell death resulting in loss of neurons [3, 71, 79-83], we

Table 3 Inflammatory load score (ILS) of each group of rats (sham-vehicle, sham-EFX, TBI-vehicle, TBI-EFX, $n=5 /$ groups) measured in the ipsilateral side of the lesion 6 hours post TBI

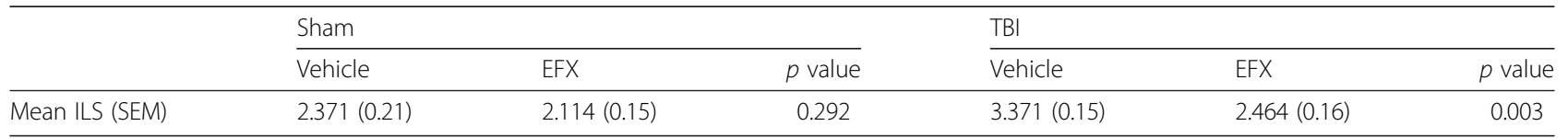

Ipsilateral cortices were analyzed with the Bio-Plex Pro ${ }^{\text {TM }}$ rat cytokine assays. The cytokines used for the score were IL-1 $a$, IL-1 $\beta$, IL-2, IL-6, IL-12, TNF-a, and GM-CSF. Data represents mean (SEM) 


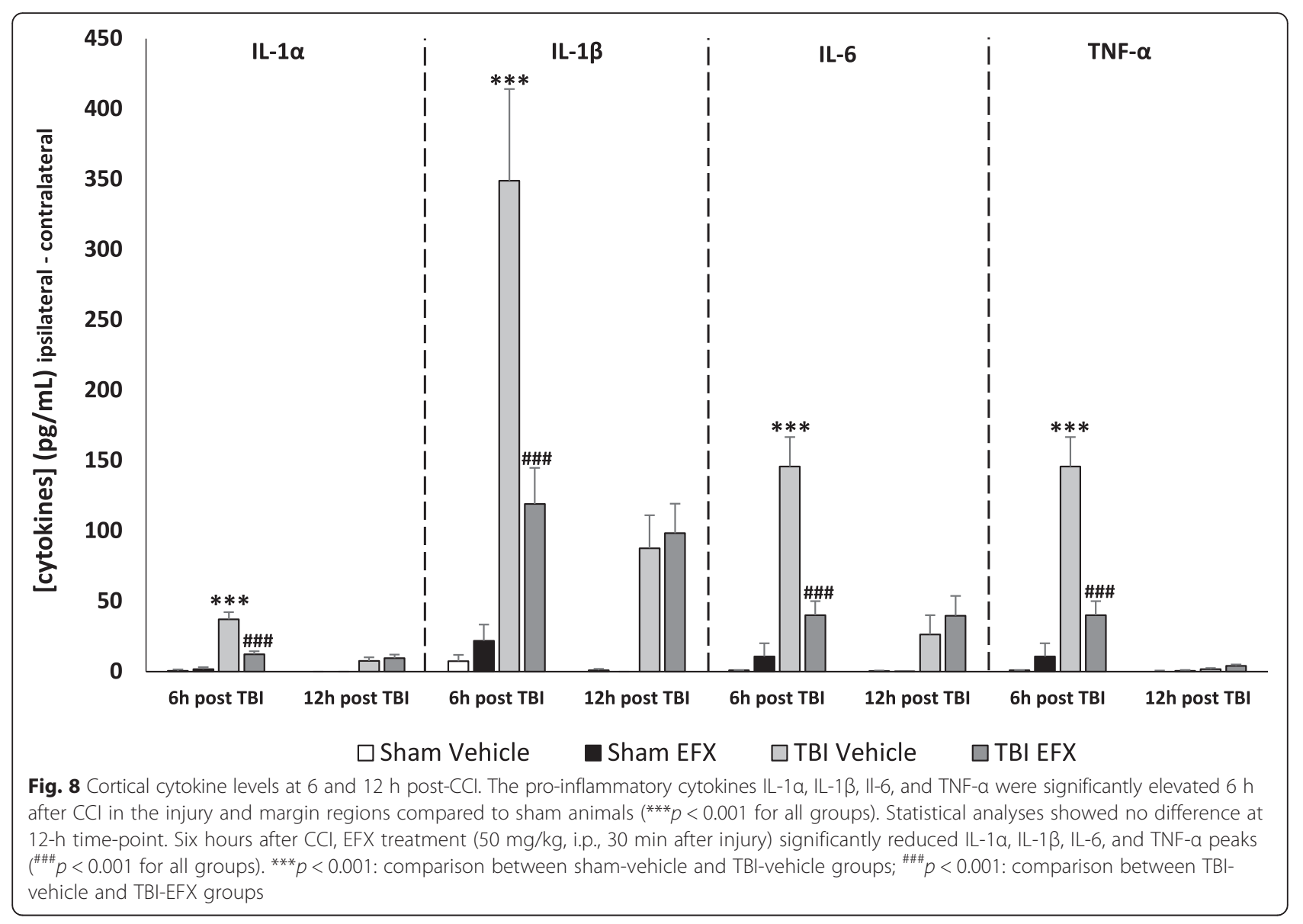

can hypothesized that EFX may exerts its neuroprotective actions, at least in part, by suppressing the expression of these cytokines which are detrimental in the acute posttraumatic period.

Experimental and clinical data show that GFAP and other intermediate filaments such as nestin and vimentin are considerably upregulated following TBI [84-86]. In our study, 2 days after TBI, there was a significant increase in GFAP immunoreactivity in the perimeter of the cortical lesion and in the subcortical white matter, reflecting increased astrocytic activation in the cortex ipsilateral to the injury site. This observation is in accordance with other studies $[64,85]$. Two days of EFX treatment significantly reduced this astrocytic activation. This is important to note because astrocytic activation increases the production of pro-inflammatory cytokines, reactive oxygen species, excitatory amino acids, and nitrogen oxides and can also induce blood brain barrier disruptions that induce immune cell infiltration [87-89]. GFAP also promotes scarring and glial proliferation which is deleterious on neuronal regeneration and recuperation [90].

Our results are in accordance with other studies that show that TSPO ligands exert neuroprotective effects and reduce neural inflammation [26, 28-30]. Girard et al. indeed showed that EFX treatment decreased messenger RNA (mRNA) expression of pro-inflammatory cytokines TNF- $\alpha$, Il- $1 \beta$, and IL- 6 and improved functional recovery in a model of peripheral nerve injury in rats and also had beneficial effects on axonal regrowth and on macrophage response [30,32]. Ravikumar et al. showed that EFX treatment reduced lipopolysaccharide (LPS)-induced IL-1 $\beta$ and IL-6 release from rat primary astrocytes in a concentration-dependent manner [91]. Daugherty et al. also showed a decrease in proinflammatory cytokines after EFX treatment in a model of multiple sclerosis [92].

Etifoxine, which is a TSPO ligand, has been shown to be a potent enhancer of neurosteroidogenesis and to induce the synthesis of pregnenolone, progesterone, and allopregnanolone $[18,20,93]$ which have demonstrated neuroprotective properties. Progesterone treatment following TBI in rats has indeed been demonstrated to reduce cerebral edema, cell death mediators expression, inflammatory response, reactive gliosis, and necrosis and to improve functional recovery [94-100]. In their studies, $\mathrm{He}$ at al. [8, 101] demonstrated that allopregnanolone significantly reduced 
neuronal loss and enhanced cognitive and behavioral recovery in a model of TBI in rats. These results suggest that EFX, a TSPO ligand, may protect neuronal function by inducing neurosteroids biosynthesis.

In addition to its action on TSPO receptor, EFX exerts a direct effect on $\mathrm{GABA}_{\mathrm{A}}$ receptor as a positive allosteric modulator [10]. This is of interest because a significant decrease in inhibitory synaptic transmission has been shown in the basolateral amygdala of rats subjected to $\mathrm{CCI}$, associated with a decrease of surface expression of $\mathrm{GABA}_{\mathrm{A}}$ receptors [102]. Furthermore, glutamatergic projections from the mediodorsal thalamic nucleus and cholinergic projections from the nucleus basalis magnocellularis to the prefrontal cortex are known to be modulated by GABA transmission [103, 104] and are highly sensitive to TBI $[8,94]$. Excessive release of glutamate and acetylcholine following TBI causes excitotoxicity that could thus be prevented by direct action of EFX on inhibitory $\mathrm{GABA}_{\mathrm{A}}$ receptors and its indirect action on the synthesis of allopregnanolone, which also potentiate GABA transmission $[105,106]$.

\section{Conclusions}

EFX treatment after TBI considerably improves functional outcomes. This effect is associated with reductions in neuronal degeneration, in glial scar formation and in microglial activation. Neuroinflammation is a major secondary injury mechanism that provides later neurodegeneration and neurologic impairments associated with TBI. We can hypothesize that functional and histological improvement of EFX-treated animals is due to its modulation of early inflammation mechanisms. These results are interesting because pre-clinical studies which combine both neurobehavioral and histological evaluations may improve the predictive value of animal models for clinical efficacy with novel neuroprotective agent [50]. In addition, the beneficial neuroprotective effects of EFX at an earliest stage of TBI might attenuate other deleterious effects such as anxiety disorders and memory disturbances which can appear several weeks later $[84,85]$.

\section{Acknowledgements}

Not applicable.

\section{Funding}

Not applicable.

\section{Availability of data and materials}

Data supporting the conclusions are presented in the manuscript. Any further information are available to scientific communities upon direct contact to the authors.

\section{Authors' contributions}

ESO designed the study, performed surgeries, performed behavioral studies and immunohistochemistry, performed statistical analyses, and wrote the manuscript. DG assisted with immunohistochemistry and performed all the image analyses. VR provided assistance with the experimental design and revised the manuscript. MV provided assistance with the experimental design and statistical analyses and revised the manuscript. All authors read and approved the final manuscript.

\section{Competing interests}

All authors are employees of Biocodex Pharmacology Department.

\section{Consent for publication}

Not applicable.

\section{Ethics approval and consent to participate}

Experiments were carried out in strict accordance with the European Community regulations for animal use in research (2010/63/EU directive) and all protocols were approved by the Local Ethical Committee (C2EA n72).

Received: 11 April 2016 Accepted: 18 August 2016

Published online: 26 August 2016

References

1. Pop V, Badaut J. A neurovascular perspective for long-term changes after brain trauma. Transl Stroke Res. 2011;2:533-45.

2. Morganti-Kossmann MC, Rancan M, Stahel PF, Kossmann T. Inflammatory response in acute traumatic brain injury: a double-edged sword. Curr Opin Crit Care. 2002;8:101-5.

3. Chen SF, Hung TH, Chen CC, Lin KH, Huang YN, Tsai HC, et al. Lovastatin improves histological and functional outcomes and reduces inflammation after experimental traumatic brain injury. Life Sci. 2007:81:288-98.

4. Kumar A, Loane DJ. Neuroinflammation after traumatic brain injury: opportunities for therapeutic intervention. Brain Behav Immun. 2012;26: 1191-201.

5. Papadopoulos V, Lecanu L. Translocator protein (18 kDa) TSPO: an emerging therapeutic target in neurotrauma. Exp Neurol. 2009;219:53-7.

6. Mclntosh TK, Juhler M, Wieloch T. Novel pharmacologic strategies in the treatment of experimental traumatic brain injury: 1998. J Neurotrauma. 1998;15:731-69.

7. Raghupathi R. Cell death mechanisms following traumatic brain injury. Brain Pathol. 2004;14:215-22.

8. He J, Hoffman SW, Stein DG. Allopregnanolone, a progesterone metabolite, enhances behavioral recovery and decreases neuronal loss after traumatic brain injury. Restor Neurol Neurosci. 2004;22:19-31.

9. Sun DA, Deshpande LS, Sombati S, Baranova A, Wilson MS, Hamm RJ, et al. Traumatic brain injury causes a long-lasting calcium (Ca2+)-plateau of elevated intracellular Ca levels and altered Ca2+ homeostatic mechanisms in hippocampal neurons surviving brain injury. Eur J Neurosci. 2008;27: 1659-72.

10. Schlichter R, Rybalchenko V, Poisbeau P, Verleye M, Gillardin J. Modulation of GABAergic synaptic transmission by the non-benzodiazepine anxiolytic etifoxine. Neuropharmacology. 2000;39:1523-35.

11. Verleye M, Gillardin JM. Effects of etifoxine on stress-induced hyperthermia, freezing behavior and colonic motor activation in rats. Physiol Behav. 2004; 82:891-7.

12. Servant D, Graziani PL, Moyse D, Parquet PJ. Treatment of adjustment disorder with anxiety: efficacy and tolerance of etifoxine in a double-blind controlled study. Encéphale. 1998;24:569-74.

13. Nguyen N, Fakra E, Pradel V, Jouve E, Alquier C, Le Guern ME, et al. Efficacy of etifoxine compared to lorazepam monotherapy in the treatment of patients with adjustment disorders with anxiety: a double-blind controlled study in general practice. Hum Psychopharmacol. 2006;21:139-49.

14. Stein DJ. Etifoxine versus al prazolam for the treatment of adjustment disorder with anxiety: a randomized controlled trial. Adv Ther. 2015;32:57-68.

15. Verleye M, Schlichter R, Gillardin JM. Interactions of etifoxine with the chloride channel coupled to the GABA(A) receptor complex. Neuroreport. 1999;10:3207-10.

16. Verleye M, Pansart $Y$, Gillardin J. Effects of etifoxine on ligand binding to GABA(A) receptors in rodents. Neurosci Res. 2002:44:167-72.

17. Hamon A, Morel A, Hue B, Verleye M, Gillardin JM. The modulatory effects of the anxiolytic etifoxine on GABA(A) receptors are mediated by the beta subunit. Neuropharmacology. 2003;45:293-303.

18. Verleye M, Akwa Y, Liere P, Ladurelle N, Pianos A, Eychenne B, et al. The anxiolytic etifoxine activates the peripheral benzodiazepine receptor and increases the neurosteroid levels in rat brain. Pharmacol Biochem Behav. 2005;82:712-20 
19. Papadopoulos V, Lecanu L, Brown RC, Han Z, Yao ZX. Peripheral-type benzodiazepine receptor in neurosteroid biosynthesis, neuropathology and neurological disorders. Neuroscience. 2006;138:749-56.

20. Wolf L, Bauer A, Melchner D, Hallof-Buestrich H, Stoertebecker P, Haen E, et al. Enhancing neurosteroid synthesis - relationship to the pharmacology of translocator protein (18 kDa) (TSPO) ligands and benzodiazepines. Pharmacopsychiatry. 2015;48:72-7.

21. Rupprecht R, Papadopoulos V, Rammes G, Baghai TC, Fan J, Akula N, et al. Translocator protein (18 kDa) (TSPO) as a therapeutic target for neurological and psychiatric disorders. Nat Rev Drug Discov. 2010;9:971-88.

22. Maeda J, Higuchi M, Inaji M, Ji B, Haneda E, Okauchi T, et al. Phasedependent roles of reactive microglia and astrocytes in nervous system injury as delineated by imaging of peripheral benzodiazepine receptor. Brain Res. 2007;1157:100-11.

23. Chauveau F, Boutin $H$, Van CN, Thominiaux C, Hantraye P, Rivron L, et al. In vivo imaging of neuroinflammation in the rodent brain with [11C]SSR180575, a novel indoleacetamide radioligand of the translocator protein (18 kDa). Eur J Nucl Med Mol Imaging. 2011;38:509-14.

24. Toth M, Little P, Arnberg F, Haggkvist J, Mulder J, Halldin C, et al. Acute neuroinflammation in a clinically relevant focal cortical ischemic stroke model in rat: longitudinal positron emission tomography and immunofluorescent tracking. Brain Struct Funct. 2015;221(3):1279-90.

25. Wang Y, Yue X, Kiesewetter DO, Niu G, Teng G, Chen X. PET imaging of neuroinflammation in a rat traumatic brain injury model with radiolabeled TSPO ligand DPA-714. Eur J Nucl Med Mol Imaging. 2014;41:1440-9.

26. Torres SR, Frode TS, Nardi GM, Vita N, Reeb R, Ferrara P, et al. Antiinflammatory effects of peripheral benzodiazepine receptor ligands in two mouse models of inflammation. Eur J Pharmacol. 2000:408:199-211.

27. Ferzaz B, Brault E, Bourliaud G, Robert JP, Poughon G, Claustre Y, et al. SSR180575 (7-chloro-N, N,5-trimethyl-4-oxo-3-phenyl-3,5-dihydro-4Hpyridazino[4,5-b]indole-1 -acetamide), a peripheral benzodiazepine receptor ligand, promotes neuronal survival and repair. J Pharmacol Exp Ther. 2002; 301:1067-78.

28. Ryu JK, Choi HB, McLarnon JG. Peripheral benzodiazepine receptor ligand PK11195 reduces microglial activation and neuronal death in quinolinic acid-injected rat striatum. Neurobiol Dis. 2005:20:550-61.

29. Veiga S, Azcoitia I, Garcia-Segura LM. Ro5-4864, a peripheral benzodiazepine receptor ligand, reduces reactive gliosis and protects hippocampal hilar neurons from kainic acid excitotoxicity. J Neurosci Res. 2005;80:129-37.

30. Girard C, Liu S, Cadepond F, Adams D, Lacroix C, Verleye M, et al. Etifoxine improves peripheral nerve regeneration and functional recovery. Proc Natl Acad Sci U S A. 2008;105:20505-10

31. Girard P, Pansart Y, Gillardin JM. Preventive and curative effects of etifoxine in a rat model of brain oedema. Clin Exp Pharmacol Physiol. 2009;36:655-61.

32. Girard C, Liu S, Adams D, Lacroix C, Sineus M, Boucher C, et al. Axonal regeneration and neuroinflammation: roles for the translocator protein 18 kDa. J Neuroendocrinol. 2012;24:71-81.

33. Lighthall JW. Controlled cortical impact: a new experimental brain injury model. J Neurotrauma. 1988:5:1-15.

34. Dixon CE, Clifton GL, Lighthall JW, Yaghmai AA, Hayes RL. A controlled cortical impact model of traumatic brain injury in the rat. J Neurosc Methods. 1991;39:253-62.

35. Anderson GD, Farin FM, Bammler TK, Beyer RP, Swan AA, Wilkerson HW, et al. The effect of progesterone dose on gene expression after traumatic brain injury. J Neurotrauma. 2011;28:1827-43.

36. Kim DH, Ko IG, Kim BK, Kim TW, Kim SE, Shin MS, et al. Treadmill exercise inhibits traumatic brain injury-induced hippocampal apoptosis. Physiol Behav. 2010;101:660-5.

37. Haber M, Abdel Baki SG, Grin'kina NM, Irizarry R, Ershova A, Orsi S, et al. Minocycline plus $\mathrm{N}$-acetylcysteine synergize to modulate inflammation and prevent cognitive and memory deficits in a rat model of mild traumatic brain injury. Exp Neurol. 2013;249:169-77.

38. Briones TL, Woods J, Rogozinska M. Decreased neuroinflammation and increased brain energy homeostasis following environmental enrichment after mild traumatic brain injury is associated with improvement in cognitive function. Acta Neuropathol Commun. 2013;1:57.

39. Robertson CS, Garcia R, Gaddam SS, Grill RJ, Cerami HC, Tian TS, et al. Treatment of mild traumatic brain injury with an erythropoietin-mimetic peptide. J Neurotrauma. 2013;30:765-74.

40. Schallert T, Upchurch M, Lobaugh N, Farrar SB, Spirduso WW, Gilliam P, et al. Tactile extinction: distinguishing between sensorimotor and motor asymmetries in rats with unilateral nigrostriatal damage. Pharmacol Biochem Behav. 1982;16:455-62.

41. Schallert T, Upchurch M, Wilcox RE, Vaughn DM. Posture-independent sensorimotor analysis of inter-hemispheric receptor asymmetries in neostriatum. Pharmacol Biochem Behav. 1983;18:753-9.

42. Freret $\mathrm{T}$, Valable $\mathrm{S}$, Chazalviel L, Saulnier R, Mackenzie ET, Petit E, et al. Delayed administration of deferoxamine reduces brain damage and promotes functional recovery after transient focal cerebral ischemia in the rat. Eur J Neurosci. 2006:23:1757-65.

43. Schallert T, Woodlee MT, Fleming SM. Disentangling multiple types of recovery from brain injury. In: Krieglstein J, editor. Pharmacology of cerebral ischemia. Stuttgart: Medpharm Scientific Publishers; 2002. p. 201-16.

44. Fleming SM, Salcedo J, Fernagut PO, Rockenstein E, Masliah E, Levine MS, et al. Early and progressive sensorimotor anomalies in mice overexpressing wild-type human alpha-synuclein. J Neurosci. 2004;24:9434-40.

45. Kaufman NA, Beare JE, Tan AA, Vitek MP, McKenna SE, Hoane MR. COG1410 an apolipoprotein E-based peptide, improves cognitive performance and reduces cortical loss following moderate fluid percussion injury in the rat. Behav Brain Res. 2010:214:395-401.

46. Schallert T, Fleming SM, Leasure JL, Tillerson JL, Bland ST. CNS plasticity and assessment of forelimb sensorimotor outcome in unilateral rat models of stroke, cortical ablation, parkinsonism and spinal cord injury. Neuropharmacology. 2000;39:777-87.

47. Woodlee MT, Asseo-Garcia AM, Zhao X, Liu SJ, Jones TA, Schallert T. Testing forelimb placing "across the midline" reveals distinct, lesion-dependent patterns of recovery in rats. Exp Neurol. 2005;191:310-7.

48. Schmued LC, Hopkins KJ. Fluoro-jade B: a high affinity fluorescent marker for the localization of neuronal degeneration. Brain Res. 2000:874:123-30.

49. Harting MT, Jimenez F, Adams SD, Mercer DW, Cox Jr CS. Acute, regional inflammatory response after traumatic brain injury: implications for cellular therapy. Surgery. 2008;144:803-13.

50. Morganti-Kossmann MC, Satgunaseelan L, Bye N, Kossmann T. Modulation of immune response by head injury. Injury. 2007;38:1392-400.

51. Fox GB, Fan L, Levasseur RA, Faden Al. Sustained sensory/motor and cognitive deficits with neuronal apoptosis following controlled cortical impact brain injury in the mouse. J Neurotrauma. 1998;15:599-614.

52. Streit WJ. The role of microglia in brain injury. Neurotoxicology. 1996;17: $671-8$

53. Mantovani A, Sica A, Sozzani S, Allavena P, Vecchi A, Locati M. The chemokine system in diverse forms of macrophage activation and polarization. Trends Immunol. 2004;25:677-86.

54. Hsieh CL, Kim CC, Ryba BE, Niemi EC, Bando JK, Locksley RM, et al. Traumatic brain injury induces macrophage subsets in the brain. Eur J Immunol. 2013:43:2010-22.

55. Perego C, Fumagalli S, De Simoni MG. Three-dimensional confocal analysis of microglia/macrophage markers of polarization in experimental brain injury. J Vis Exp. 2013. doi:10.3791/50605

56. Hernandez-Ontiveros DG, Tajiri N, Acosta S, Giunta B, Tan J, Borlongan CV. Microglia activation as a biomarker for traumatic brain injury. Front Neurol. 2013;4:30

57. Ansari MA. Temporal profile of $M 1$ and $M 2$ responses in the hippocampus following early $24 \mathrm{~h}$ of neurotrauma. J Neurol Sci. 2015;357:41-9.

58. Turtzo LC, Lescher J, Janes L, Dean DD, Budde MD, Frank JA. Macrophagic and microglial responses after focal traumatic brain injury in the female rat. J Neuroinflammation. 2014:11:82.

59. Wang G, Zhang J, Hu X, Zhang L, Mao L, Jiang X, et al. Microglia/ macrophage polarization dynamics in white matter after traumatic brain injury. J Cereb Blood Flow Metab. 2013;33:1864-74.

60. Rodriguez-Rodriguez A, Egea-Guerrero JJ, Murillo-Cabezas F, Carrillo-Vico A. Oxidative stress in traumatic brain injury. Curr Med Chem. 2014;21: $1201-11$.

61. Loane DJ, Kumar A. Microglia in the TBI brain: the good, the bad, and the dysregulated. Exp Neurol. 2016;275(Pt 3):316-27.

62. Goodman JC, Robertson CS, Grossman RG, Narayan RK. Elevation of tumor necrosis factor in head injury. J Neuroimmunol. 1990;30:213-7.

63. Helmy A, De Simoni MG, Guilfoyle MR, Carpenter KL, Hutchinson PJ. Cytokines and innate inflammation in the pathogenesis of human traumatic brain injury. Prog Neurobiol. 2011;95:352-72

64. Perez-Polo JR, Rea HC, Johnson KM, Parsley MA, Unabia GC, Xu G, et al. Inflammatory consequences in a rodent model of mild traumatic brain injury. J Neurotrauma. 2013;30:727-40. 
65. Semple BD, Bye N, Rancan M, Ziebell JM, Morganti-Kossmann MC. Role of CCL2 (MCP-1) in traumatic brain injury (TBI): evidence from severe TBI patients and CCL2-/- mice. J Cereb Blood Flow Metab. 2010;30:769-82.

66. Mukherjee S, Katki K, Arisi GM, Foresti ML, Shapiro LA. Early TBI-induced cytokine alterations are similarly detected by two distinct methods of multiplex assay. Front Mol Neurosci. 2011;4:21.

67. Dalgard CL, Cole JT, Kean WS, Lucky JJ, Sukumar G, McMullen DC, et al. The cytokine temporal profile in rat cortex after controlled cortical impact. Front Mol Neurosci. 2012;5:6

68. Lu KT, Wang YW, Wo YY, Yang YL. Extracellular signal-regulated kinasemediated IL-1-induced cortical neuron damage during traumatic brain injury. Neurosci Lett. 2005;386:40-5.

69. Pu B, Xue Y, Wang Q, Hua C, Li X. Dextromethorphan provides neuroprotection via anti-inflammatory and anti-excitotoxicity effects in the cortex following traumatic brain injury. Mol Med Rep. 2015;12:3704-10.

70. Taupin V, Toulmond S, Serrano A, Benavides J, Zavala F. Increase in IL-6, IL-1 and TNF levels in rat brain following traumatic lesion. Influence of pre- and post-traumatic treatment with Ro5 4864, a peripheral-type (p site) benzodiazepine ligand. J Neuroimmunol. 1993;42:177-85.

71. Holmin S, Mathiesen T. Intracerebral administration of interleukin-1beta and induction of inflammation, apoptosis, and vasogenic edema. J Neurosurg. 2000;92:108-20

72. Venters HD, Dantzer R, Kelley KW. A new concept in neurodegeneration: TNFalpha is a silencer of survival signals. Trends Neurosci. 2000;23:175-80.

73. Patel HC, Boutin H, Allan SM. Interleukin-1 in the brain: mechanisms of action in acute neurodegeneration. Ann N Y Acad Sci. 2003;992:39-47.

74. Raivich G, Liu ZQ, Kloss CU, Labow M, Bluethmann H, Bohatschek M. Cytotoxic potential of proinflammatory cytokines: combined deletion of TNF receptors TNFR1 and TNFR2 prevents motoneuron cell death after facial axotomy in adult mouse. Exp Neurol. 2002;178:186-93.

75. Stover JF, Schoning B, Beyer TF, Woiciechowsky C, Unterberg AW. Temporal profile of cerebrospinal fluid glutamate, interleukin-6, and tumor necrosis factor-alpha in relation to brain edema and contusion following controlled cortical impact injury in rats. Neurosci Lett. 2000;288:25-8.

76. Tehranian R, Andell-Jonsson S, Beni SM, Yatsiv I, Shohami E, Bartfai T, et al. Improved recovery and delayed cytokine induction after closed head injury in mice with central overexpression of the secreted isoform of the interleukin-1 receptor antagonist. J Neurotrauma. 2002;19:939-51.

77. Baratz R, Tweedie D, Wang JY, Rubovitch V, Luo W, Hoffer BJ, et al. Transiently lowering tumor necrosis factor-a synthesis ameliorates neuronal cell loss and cognitive impairments induce by minimal traumatic brain injury in mice. J Neuroinflammation. 2015:7:12-45.

78. d'Avila JC, Lam TI, Bingham D, Shi J, Won SJ, Kauppinen TM, et al. Microglial activation induced by brain trauma is suppressed by post-injury treatment with a PARP inhibitor. J Neuroinflammation. 2012;9:31.

79. Kim KS, Wass CA, Cross AS, Opal SM. Modulation of blood-brain barrier permeability by tumor necrosis factor and antibody to tumor necrosis factor in the rat. Lymphokine Cytokine Res. 1992;11:293-8.

80. Touzani $\mathrm{O}$, Boutin $\mathrm{H}$, Chuquet J, Rothwell N. Potential mechanisms of interleukin-1 involvement in cerebral ischaemia. J Neuroimmunol. 1999; 100:203-15

81. Zhang X, Chen Y, Jenkins LW, Kochanek PM, Clark RS. Bench-to-bedside review: apoptosis/programmed cell death triggered by traumatic brain injury. Crit Care. 2005;9:66-75.

82. Ziebell JM, Morganti-Kossmann MC. Involvement of pro- and antiinflammatory cytokines and chemokines in the pathophysiology of traumatic brain injury. Neurotherapeutics. 2010;7:22-30.

83. Woodcock T, Morganti-Kossmann MC. The role of markers of inflammation in traumatic brain injury. Front Neurol. 2013:4:18.

84. Nylen K, Ost M, Csajbok LZ, Nilsson I, Blennow K, Nellgard B, et al. Increased serum-GFAP in patients with severe traumatic brain injury is related to outcome. J Neurol Sci. 2006:240:85-91.

85. Ekmark-Lewen $\mathrm{S}$, Lewen A, Israelsson C, Li GL, Farooque M, Olsson Y, et al. Vimentin and GFAP responses in astrocytes after contusion trauma to the murine brain. Restor Neurol Neurosci. 2010;28:311-21.

86. Plog BA, Dashnaw ML, Hitomi E, Peng W, Liao Y, Lou N, et al. Biomarkers of traumatic injury are transported from brain to blood via the glymphatic system. J Neurosci. 2015;35:518-26.

87. Johnstone M, Gearing AJ, Miller KM. A central role for astrocytes in the inflammatory response to beta-amyloid; chemokines, cytokines and reactive oxygen species are produced. J Neuroimmunol. 1999;93:182-93.
88. Shafer RA, Murphy S. Activated astrocytes induce nitric oxide synthase-2 in cerebral endothelium via tumor necrosis factor alpha. Glia. 1997;21:370-9.

89. Tanaka M, Sotomatsu A, Yoshida T, Hirai S, Nishida A. Detection of superoxide production by activated microglia using a sensitive and specific chemiluminescence assay and microglia-mediated PC12h cell death. J Neurochem. 1994;63:266-70.

90. Wei LC, Shi M, Chen LW, Cao R, Zhang P, Chan YS. Nestin-containing cells express glial fibrillary acidic protein in the proliferative regions of central nervous system of postnatal developing and adult mice. Brain Res Dev Brain Res. 2002;139:9-17.

91. Ravikumar B, Crawford D, Dellovade T, Savinainen A, Graham D, Liere P, et al. Differential efficacy of the TSPO ligands etifoxine and XBD-173 in two rodent models of Multiple Sclerosis. Neuropharmacology. 2016;108:229-37.

92. Daugherty DJ, Selvaraj V, Chechneva OV, Liu XB, Pleasure DE, Deng W. A TSPO ligand is protective in a mouse model of multiple sclerosis. EMBO Mol Med. 2013;5:891-903.

93. do Rego JL, Vaudry D, Vaudry H. The non-benzodiazepine anxiolytic drug etifoxine causes a rapid, receptor-independent stimulation of neurosteroid biosynthesis. PLoS One. 2015:10:e0120473.

94. Roof RL, Duvdevani R, Braswell L, Stein DG. Progesterone facilitates cognitive recovery and reduces secondary neuronal loss caused by cortical contusion injury in male rats. Exp Neurol. 1994;129:64-9.

95. Galani R, Hoffman SW, Stein DG. Effects of the duration of progesterone treatment on the resolution of cerebral edema induced by cortical contusions in rats. Restor Neurol Neurosci. 2001;18:161-6.

96. Grossman KJ, Goss CW, Stein DG. Effects of progesterone on the inflammatory response to brain injury in the rat. Brain Res. 2004;1008:29-39.

97. Djebaili M, Guo Q, Pettus EH, Hoffman SW, Stein DG. The neurosteroids progesterone and allopregnanolone reduce cell death, gliosis, and functional deficits after traumatic brain injury in rats. J Neurotrauma. 2005; 22:106-18.

98. VanLandingham JW, Cutler SM, Virmani S, Hoffman SW, Covey DF, Krishnan K, et al. The enantiomer of progesterone acts as a molecular neuroprotectant after traumatic brain injury. Neuropharmacology. 2006;51:1078-85.

99. Pettus EH, Wright DW, Stein DG, Hoffman SW. Progesterone treatment inhibits the inflammatory agents that accompany traumatic brain injury. Brain Res. 2005:1049:112-9.

100. Cutler SM, VanLandingham JW, Murphy AZ, Stein DG. Slow-release and injected progesterone treatments enhance acute recovery after traumatic brain injury. Pharmacol Biochem Behav. 2006;84:420-8.

101. He J, Evans CO, Hoffman SW, Oyesiku NM, Stein DG. Progesterone and allopregnanolone reduce inflammatory cytokines after traumatic brain injury. Exp Neurol. 2004;189:404-12.

102. Almeida-Suhett CP, Prager EM, Pidoplichko V, Figueiredo TH, Marini AM, Li $Z$, et al. Reduced GABAergic inhibition in the basolateral amygdala and the development of anxiety-like behaviors after mild traumatic brain injury. PLoS One. 2014;9:e102627.

103. Khateb A, Fort $P$, Williams S, Serafin M, Muhlethaler M, Jones BE. GABAergic input to cholinergic nucleus basalis neurons. Neuroscience. 1998;86:937-47.

104. Romanides AJ, Duffy P, Kalivas PW. Glutamatergic and dopaminergic afferents to the prefrontal cortex regulate spatial working memory in rats. Neuroscience. 1999:92:97-106.

105. Akk G, Covey DF, Evers AS, Steinbach JH, Zorumski CF, Mennerick S. Mechanisms of neurosteroid interactions with $G A B A(A)$ receptors. Pharmacol Ther. 2007:116:35-57.

106. Schumacher M, Mattern C, Ghoumari A, Oudinet JP, Liere P, Labombarda F, et al. Revisiting the roles of progesterone and allopregnanolone in the nervous system: resurgence of the progesterone receptors. Prog Neurobiol. 2014:113:6-39. 